\title{
Análise das repercussões do Programa de Acolhimento aos I rmãos de Bebês Internados em UTI Neonatal: "Lembraram-se de Mim!"
}

\author{
Analysis of the repercussion of the Program \\ of Sibling Visits to the N ewborn Babies in NICU: \\ "They remembered me!"
}

Denise Streit M orsch 1

Juliana Delamonica 2
1 Clínica Perinatal Laranjeiras. Rua das Laranjeiras 445 , 22240-002, Rio de Janeiro RJ. dmorsch@globo.com 2 Curso de Especialização em Psicossomática Contemporânea, Universidade Gama Filho.
Abstract This article analyse with an exploration form the repercussion of the authors observations and dates of some interviews with staff and parents during the activities from the Sibling's Assistance to the $\mathrm{N}$ ewborns in a N eonatal Intensive Care U nit Program "They remembered me!" which is occurring for already eight years in a private dinic in Rio de Janeiro. The observation of the sibling's visits, interviews with the staff and parents during the period of the baby's hospitalization and after his discharge from hospital made possible the detection of different behaviours in the age of the sibling's and accordant with the parents the siblings participation had improved a subtle beginning for a fraternal bond, helping to understand the truly situation that the whole family was living, demystifying fantasies in the causes of the newborn admission, reducing the family anxiety providing better trust to the siblings and family. These data lead us to notice that this recommended intervention makes it easier to establish the humanized process in the neonatal intensive care.

Key words Intensive neonatal care, Humanized care, Family care, Fraternal bond
Resumo Este artigo analisa de forma exploratória as repercussões do Programa de A colhimento aos I rmãos de Bebês I nternados em UTI N eonatal: "Lembraram-se de M im!", que vem ocorrendo há oito anos numa Unidade de Tratamento Intensivo N eonatal, de uma clínica privada, na cidade do Rio de Janeiro. Por meio da observação das visitas dos irmãos e das falas dos pais durante o período de internação do bebê e no pós-alta hospitalar foi possível registrar mudanças de conduta nos pais, mostrando uma maior participação nos cuidados com o filho internado; observar condutas diversas de acordo com as diferentes faixas etárias dos irmãos; acompanhar novas percepções da equipe em relação aos bebês e suas famílias. Tais dados mostram que se trata de uma intervenção recomendada para facilitar o processo de humanização nos cuidados intensi vos neonatais.

Palavras-chave Cuidados intensivos neonatais, H umanização, Cuidados com a família, Vínculos fraternos 


\section{Introdução}

O Programa de Acolhimento aos I rmãos de Bebês I nternados em Unidade de Tratamento Intensivo N eonatal: “Lembraram-se de M im!", implantado no ano de 1996, numa U nidade de Cuidados I ntensivos N eonatais de uma clínica privada da cidade do Rio de Janeiro, é pioneiro no país quanto ao modelo que apresenta e sua implantação vem sendo recomendada (Brasil, 2002). Isso exige que suas propostas e diretrizes de funcionamento sejam pensadas, uma vez que há escassez de discussões sobre seus resultados. Alguns relatos da ocorrência dessas visitas são encontrados em artigos nacionais (Scochi et al., 2003) e em comunicações pessoais, sempre com a coordenação ou acompanhamento dos serviços de enfermagem ou médico de unidades públicas como ocorre no Hospital Universitário - U nidade M aterno Infantil da Universidade Federal do $M$ aranhão. Programas similares são encontrados em diferentes lugares do mundo, também com acompanhamento dos irmãos por equipes das Unidades de Tratamento Intensivo $\mathrm{N}$ eonatais, ou mesmo pelas famílias que optam pelo horário e duração mais conveniente para a sua realização (Barrera et al., 1993; Klaus \& Kennell, 1993; Kimberly et al., 2003; Oakes, 1993; Larguia, 2005). Em alguns desses serviços as visitas tornaram-se diárias, inclusive com o uso de sistemas mais sofisticados como de videoconferências (Gray, 2000). Em nosso país o programa passou a ser uma sugestão de atividades dentro do Programa de Atenção Humanizada ao Recém-nascido de Risco - M étodo Canguru. Já nos Estados Unidos ele érecomendado pela Academia Americana de Pediatria (Committee on fetus and newborn - Postpartum (N eonatal) Sibling Visitation, 1985).

Ao darmos início a este programa, os pais de bebês que se encontravam internados estabeleceram, junto com a equipe, normas para a realização das visitas. Posteriormente, essas normas foram comparadas com aquelas sugeridas pela Academia Americana de Pediatria, mostrando uma grande semelhança. No programa desenvolvido nesses anos, 0 acolhimento aos irmãos se dá através da equipe de psicologia do hospital, com atividades próprias da infância, envolven do o brincar e desenhar, com o intuito de favorecer a comunicação entre visitantes e equipe, bem como facilitar, aos irmãos mais velhos, a compreensão da situação. Essas atividades, portanto, instrumentam a ob- servação de aspectos comportamentais e afetivos do irmão visitante, determinando, em conseqüência, as intervenções necessárias.

A implantação desse programa ocorreu a partir da solicitação dos irmãos dos bebês, que encaminhavam desenhos, presentes ou bilhetes para serem colocados nas incubadoras, demandando uma maior participação na hospitalização do recém-nascido. Outras crianças freqüentavam a sala de espera da UTI neonatal, participando de tudo que ocorria no local - chegada de bebês, pais chorando, equipe preocupada. Estas crianças buscavam pequenos espaços na sua interação com a equipe para poder "espiar" a UTI ou receber al gumas informações. Somado a isso os pais queixavam-se, freqüentemente, do surgimento de dificuldades relacionadas à escola, às rotinas diárias, distúrbios alimentares, de sono, entre outros a partir da internação do bebê (M orsch et al., 1997).

Foi então avaliada com a equipe da instituição a participação desses integrantes da família na rotina de visitas à UTI neonatal, buscando atender as suas demandas e trabal har os seus sentimentos, provocados pela chegada do bebê e sua internação. Da implantação do programa, com visitas semanais, em horário estabelecido pela equipe da UTI N eonatal, até os dias de hoje, já foram acolhidas mais de 250 crianças, adolescentes e mesmo irmãos adultos. Não existem limites em relação à idade ou à presença de situações especiais como patologias psiquiátricas, déficits intelectuais ou demais comprometimentos das crianças, para sua participação no programa. Pequenos irmãos, com idade inferior a dois anos e também irmãos com dificuldades em diferentes áreas do desenvolvimento, alguns sugerindo déficit cognitivo, quadros psicóticos ou mesmo transtornos invasivos do desenvolvimento participaram e surpreenderam em suas condutas. Essas questões não foram impeditivas de um bom andamento das atividades nem foram necessárias intervenções especiais tais como horário ou acompanhamento individualizado. Acredita-se, entretanto, que nestas situações, é recomendável uma supervisão mais constante por parte dos profissionais da equipe, com a preocupação de atender necessidades destas crianças pequenas ou especiais, no grupo ou mesmo no espaço da UTI. Quando o número de irmãos adolescentes é maior, eles são recebidos um pouco antes de ter início o trabalho com as crianças. Assim, podem ser mais adequadamente acompanhados e orientados em relação às suas dúvidas e 
fantasias. Tal procedimento não inviabiliza o encontro entre os dois grupos - adolescentes e crianças - dentro das Unidades de Tratamento Intensivo ou mesmo nos corredores do hospital, o que consideramos muito indicado.

Os objetivos do programa compreendem: - possibilitar a participação do irmão no processo de internação do recém-nascido em cuidados intensivos neonatais, oferecendo um espaço de acolhimento à ansiedade e demais sentimentos provocados pela situação;

- informar sobre o quadro clínico do bebê, suas necessidades de cuidados especializados, oferecendo uma melhor compreensão do que se passa, neste momento;

- promover a continuidade dos diferentes papéis e funções no sistema familiar;

- criar uma rede de apoio que ofereça aos irmãos um suporte para a continuidade de suas rotinas diárias.

0 programa prevê visitas semanais com duas horas de duração, divididas em três momentos. 0 primeiro momento se destina à recepção, ao esclarecimento de dúvidas relativas à internação e realização de atividades lúdicas e desenhos. Sabe-se que, da mesma forma que para seus pais, a vinda do bebê para os cuidados intensivos provoca nos irmãos uma reação de estranhamento. Surgem sentimentos agressivos, pensamentos relacionados a uma suposta culpa pela internação do pequeno irmão, parecendo que suas fantasias sempre comuns na ocorrência da gestação, de não aceitação do irmão tornaram-se realidade, determinando a fragilidade ou a doença do recém-nascido.

A participação nessas atividades iniciais tem como finalidade permitir que, sentindo-se protegidos pelas atividades lúdicas, possam contar sobre suas sensações e percepções, enquanto experimentam, da parte do serviço, a aceitação destas fantasias. A grande preocupação por parte dos psicólogos é de apenas oferecer suporte e acolhimento com uma atitude receptiva, utilização de pequenas frases ou expressões verbais que lhes informem sobre a compreensão e aceitação destes seus sentimentos, já que essas crianças não se encontram, neste programa, num processo psicoterápico.

Configurando o segundo momento, ao se mostrarem dispostas a visitarem seus irmãos, as crianças são orientadas quanto à assepsia, especialmente das mãos e acompanhadas até a incubadora ou o berço aquecido em que se encontra o recém-nascido. N esse momento levam consigo, para presentearem o bebê, os desenhos que fizeram durante as conversas, o que lhes serve de elemento de segurança e estabilidade por tratar-se de um objeto por elas confeccionado.

São programados em torno de vinte minutos para as crianças menores permanecerem junto do bebê. 0 tempo se torna maior à medida que aumenta a idade do visitante. A equipe de psicologia busca facilitar a comunicação da criança visitante com a equipe, explicar como funciona a aparelhagem utilizada pelo bebê, responder às suas dúvidas, avaliar necessidades de outras intervenções e permitir que a família encontre seus próprios caminhos para viver este encontro.

No tempo restante, o terceiro momento, são discutidas as experiências ocorridas durante a visita.

Acreditamos que desta forma partil ha-se da preocupação de M ontagu (1988) e tantos outros autores que discorreram sobre as relações fraternas (Bank et al., 1988; Rufo, 2003):

Embora já tenha sido escrito muito a respeito dos vínculos entre a mãe e o recém-nascido e entre os pais e o filho, é importante reconhecer que os laços entre os irmãos e o novo membro da família são tão importantes para o desenvolvimento dos relacionamentos familiares e fraternais quanto os outros. Os que já presenciaram a ligação que se forma entre irmãos, um com apenas vinte meses e outro recém-nascido, a surpresa, 0 prazer e 0 interesse que se manifestam diante desse novo fenômeno, alimentam poucas dúvidas de que a qualidade do relacionamento a desenvolver-se dali por diante entre eles está associada a esse vínculo inicial.

\section{Método do estudo}

Este trabal ho utilizou a metodologia da observação participante na obtenção de dados do que ocorre durante as atividades que fazem parte do programa de acolhimento aos irmãos dos bebês internados em UTI Neonatal. 0 acompanhamento dos gestos, das condutas, das representações gráficas, do uso dos brinquedos e seus significados e nossa compreensão da relação fraterna numa situação de crise familiar pela doença ou fragilidade de um de seus membros fizeram parte de nossos critérios observacionais. Ou seja, todas as expressões dos irmãos foram valorizadas e pensadas a partir de uma visão que privilegia a psicologia do desenvolvimento, com paradigmas da faixa evolutiva ou 
do nível de funcionamento dos visitantes e o significado da relação fraterna. Também recorremos à psicologia clínica no entendimento de situação de crise, hospitalização, rivalidade, sinais de agressividade, depressão, entre outros. Todas as informações foram coletadas no campo da assistência da instituição ou pela psicóloga responsável pela implantação do programa ou pela psicóloga que durante 18 meses (entre junho de 2003 e dezembro de 2004) acompanhou o programa e suas atividades, participou ativamente dos encontros com os irmãos e realizou registros em um diário de campo. Esta última aplicou questionários aos pais de cinco bebês ainda durante a internação e cinco no pós-alta do bebê. Estes questionários contavam com seis questões, todas solicitando comentários por escrito. Da mesma forma aplicou questionários com dez integrantes da equipe de cuidados neonatais, com cinco questões, novamente solicitando respostas comentadas. Os questionários com a equipe envolveram médicos, enfermeiras, auxiliares de enfermagem e auxiliares administrativos. Todos os entrevistados da equipe acompanharam as atividades no ambiente intensivo durante 0 desenrolar de suas atividades. A penas dois foram respondidos por profissionais com menos de cinco anos de trabalho na clínica.

\section{Resultados da observação}

Os resultados da observação foram organizados em três temas a partir dos conteúdos levantados nos registros do diário de campo ou da observação clínica realizada durante os oito anos de sua realização. Os temas basearam-se na repetição de determinados fenômenos registrados: repercussões na família, no irmão visitante e no comportamento observado nas diferentes faixas etárias dos irmãos visitantes.

\section{Repercussões na família}

Ao serem apresentados ao programa, muitos pais questionam o valor e adequação de trazerem seu(s) filho(s) para a visita. M uitos deles comentam sobre a pouca idade do irmão, sobre sua capacidade para compreender o que acontece com o bebê. Acreditam que conhecer o bebê com sondas, com o respirador ou cateter pode trazer malefícios para as crianças, projetando nos filhos mais velhos suas próprias preocupações. N ossa conduta nestes primeiros encontros é lhes oferecer todas orientações e informações necessárias para que eles possam decidir a participação ou não das demais crianças da família, no programa. São deixados à vontade para escolherem o momento que julgarem mais indicado para a visita acontecer. Também são informados de que mesmo comparecendo, a criança só entrará se assim o desejar.

A participação no programa e a conseqüente avaliação do que se passou traz relatos espontâneos dos pais e mesmo dos avós que freqüentam os cuidados intensivos:

- a visita dos irmãos permite a família se reunir no ambiente de cuidados intensivos neonatais resgatando os papéis e funções de cada um de seus membros;

- a visita do filho mais velho permite que fantasias parentais quanto à fragilidade do bebê diminuam, determinando a observação das competências do mesmo, o que facilita a proximidade dos pais com o recém-nascido e ao mesmo tempo diminui o medo em tocar o bebê ou mesmo falar com ele;

- as famílias cujas crianças participam ativamente do programa permaneceram com um contato pós-alta mais freqüente, enviando notícias e relatos afirmando a importância deste trabalho;

- para aquelas famílias cujos recém-nascidos apresentam síndrome ou más-formações, estes encontros prepararam os irmãos para as novas exigências desta história familiar.

\section{Repercussões no irmão visitante}

A observação de fantasias de abandono, temor à perda do amor parental, a presença de insegurança podem ser acompanhadas nas primeiras visitas de alguns dos irmãos. Ao chegarem ao hospital mostram sentimentos ambivalentes em relação aos pais e demais figuras de autoridade, podem apresentar comportamentos de difícil manejo, depressão, estranhamento, ou comportamentos reativos ( mostram-se exigentes e opositoras ou então totalmente confortáveis com a situação, cordatas, "boazinhas"). Por outro lado pode ser observada insegurança quanto aos lugares que o irmão e ele mesmo ocuparão nessa nova configuração familiar, (começam a contar que precisaram ir para a casa dos avós, mudaram de quarto, a mãe não vai mais buscá-los na escola); frustração e tristeza por não levarem o bebê para casa, aliada à ausência dos pais. A falta de informações sobre a internação dá lugar a fantasias sobre sua culpa 
na ocorrência da situação de risco do bebê (inclusive com comentários como eu sou um menino mau).

A partir da participação no programa, as condutas se modificam:

- não foram observados comportamentos de estresse nas crianças que partici param das atividades do programa. Ao se sentirem acolhidas e orientadas recebem suporte para 0 enfrentamento da situação;

- poucos dias após as visitas à UTI neonatal, os pais passam a relatar mudanças, como diminuição das queixas da escola e desaparecimento dos distúrbios psicossomáticos surgidos a partir do nascimento do bebê. Com freqüência os pais relatam que, após as visitas, seus filhos mais velhos estimulam a permanência materna e paterna no hospital;

- o fato de a equipe os receber lhes oferece a garantia de que não são os responsáveis pelo que aconteceu ao irmão;

- a presença de patologias como déficits intelectuais, síndromes ou quadros emocionais, no irmão mais velho, não mostrou contra-indicação e sim confirmou o valor e necessidade da visita; - o trabalho lúdico anterior à visita oferece um lugar para que dúvidas e sentimentos sejam expressos. A realização destas atividades acompanhadas de informações participa do processo de elaboração desta situação;

- faixas etárias diferentes necessitam cuidados e disponibilidade diferenciados da equipe que recebe os irmãos. Em relação a este item consideramos adequado criar um novo subtítulo, pois se trata de um material que ajuda na compreen são das diferentes necessidades das crianças visitantes.

\section{Comportamentos nas diferentes faixas etárias dos irmãos visitantes}

As crianças de um a três anos chegam para 0 encontro com o irmão ansiosas e preocupadas. Olham ao redor, resistem a conversar com as psicólogas, permanecem junto dos pais ou avós, mas gostam de desenhar. Seus desenhos mostram bolas que representam o bebê ou a barriga da mãe, rabiscos feitos com tanta força que podem rasgar o papel - a família voltando para casa, a família sem o bebê, alguns bichos soltando fogo pelo nariz, baleias e tubarões comendo peixes pequenos... Já na UTI Neonatal dirigem-se à incubadora com pressa, algumas vezes precisam ser um pouco contidas, erguidas no colo, postas em cima de cadeiras para poderem ver melhor o bebê, na incubadora. Logo querem pegá-lo e são orientadas por seus pais com frases como "calma que ele é pequenininho" ou "bem devagar, hein! Olha a mãozinha dele". Permanecem na maioria das vezes pouco tempo com o bebêe logo retornam para as atividades propostas em nosso primeiro momento. A presentam grande necessidade em tocar o bebê, provavelmente para se certificarem de que ele é real. N ossa observação mostra que são extremamente cuidadosos nesta proximidade.

Entre os três e seis anos, as crianças chegam também ansiosas e preocupadas, acompanhadas dos pais, avós ou amigos da família. O lham as mesinhas, sentam-se e perguntam se podem desenhar. Alguns apresentam certa resistência no relacionamento com a equipe, perguntam sobre o quadro clínico do bebê, o motivo da internação, prestam atenção às explicações dadas sobre os cuidados que os bebês vêm recebendo. Desenham famílias, bebês na incubadora (conhecida através de fotos) e quando acabam pedem para entrar na UTI. A proximam-se devagar, olham o bebê antes de tocá-lo, sorriem muito e permanecem por muito tempo ao lado da incubadora. Gostam de ficar junto do bebê, observam a rotina dos cuidados, questionam os movimentos e expressões dos bebês. Não demonstram resistência quanto a sair da UTI, pois desejam realizar novos desenhos e comentam: "Semana que vem eu posso vir de novo?" Ou: "Ele deve se sentir muito sozinho!"

As crianças com sete a onze anos chegam geralmente acompanhadas pelo pai, pois a mãe se encontra junto do bebê. A parentemente tímidas e ansiosas observam muito, olham as pessoas que entram e saem da UTI. Algumas, inquietas, demonstram ansiedade em realizar as atividades. Trazem muitas perguntas acerca da internação e demonstram já ter conhecimento sobre o motivo que levou o bebêa ficar internado. Sabem como é uma incubadora e comumente têm informações sobre o peso do bebê. Permanecem menos tempo desenhando e quando o fazem representam a mãe grávida, criam histórias em quadrinhos com super-heróis e vilões, desenham a incubadora, manipulam e cuidam dos bonecos disponíveis que lembram os bebês pequenos, em suas incubadoras. Alguns perguntam: e quando morre o que acontece?, Algum bebê já morreu aqui? Entram lentamente na UTI, observando o local, os outros bebês e olham mais tempo para o bebê antes de tocá-lo. Perguntam se podem pegar no 
colo, puxam rapidamente uma cadeira e sentam-se, prontos para recebê-lo. O bservam os procedimentos, perguntam como funciona 0 monitor e o observam. Fornecem explicações próprias para al guns dos comportamentos dos bebês. Comumente permanecem com 0 irmão até 0 final do horário da visita.

Os adolescentes chegam com o pai ou sozinhos. A proximam-se reservadamente da equipe, limitam-se a ouvir o que lhes é dito. Alguns poucos exploram os brinquedos, arrumam os bonecos em suas incubadoras, os vestem, mas procuram realizar isto como uma forma de "ajudar as crianças menores", mesmo não sendo seus irmãos. Em geral desenham apenas quando acompanham um irmão mais novo. Ansiosos, são instruídos acerca do ambiente hospitalar, do quadro clínico do bebê e assim que recebem tais informações entram na unidade. Lembram que seus pais os mantêm informados a respeito da internação. Permanecem todo o tempo previsto para a visita com o irmão no colo ou acariciando-o. Perguntam sobre o quadro clínico do bebê e sobre a alta.

Os irmãos adultos dirigem-se à equipe e perguntam se é necessário conversar com a psicóloga. São orientados acerca da assepsia, sobre o quadro clínico do bebê e quanto à disponibilidade da equipe em caso de dúvidas. Ao se aproximarem do bebê permanecem muito tempo olhando para seu corpo, para seu rosto equestionam se podem tocá-lo. Emocionam-se muito, choram, mas ao mesmo tempo val orizam muito o investimento que o bebê faz para viver, dar conta de suas necessidades. N ota-se que a presença do bebê os remete a questões próprias da maternidade ou paternidade, levando-os a se questionarem sobre estas funções, realizam comentários sobre as mesmas. Ou lembram de seus próprios filhos, passam a relatar sobre os mesmos para os profissionais da equipe ou demais familiares que lá se encontram.

\section{Resultados dos questionários}

Os questionários foram respondidos por escrito, de forma anônima, facilitando a possibilidade de surgirem críticas ou indicação de pontos negativos do programa. Com os pais foram aplicados dez questionários contendo seis perguntas. Cinco famílias estavam ainda com seus bebês internados enquanto as outras cinco famílias já haviam recebido alta. A idéia desses dois grupos baseou-se no fato de que seria importante obter informações sobre repercussões do programa quando o bebê já estivesse no ambiente familiar. 0 estudo das respostas nestes dois momentos não mostrou diferenças quanto ao seu conteúdo. Todas as famílias demonstraram satisfação em responder, elogiaram o trabalho e falaram dos resultados com seu fiIho mais velho, com a família e com o bebê.

Para a equipe foram aplicados dez questionários, cada um com cinco perguntas acerca do programa. Participaram do questionário enfermeiras, médicos, técnicos de enfermagem e auxiliares administrativos. Todos os entrevistados acompanharam as atividades no ambiente intensivo durante o desenrolar de suas atividades nos cuidados intensivos neonatais. Apenas dois foram respondidos por profissionais com menos de cinco anos de trabalho na clínica. 0 tempo de instituição foi contemplado na busca de se estabelecer o tempo de observação da atividade. Isso pareceu importante para se ter claro se as respostas surgiam em virtude de um acompanhamento mais longo do programa ou de uma motivação recente para com o mesmo. N os resultados não foram encontradas diferenças devido à função ou tempo de serviço. De acordo com os comentários, foram levantadas, para os dois grupos, áreas de abrangência do conteúdo e organizadas al gumas falas representativas destas idéias.

\section{Respostas dos pais}

Quanto ao conteúdo das respostas foram pontuadas al gumas falas.

Em relação ao programa os comentários das famílias mostraram-se positivos: Acho maravilhoso, pois se cria toda uma expectativa com relação à chegada do bebê em casa, e de repentea mãe volta, sem barriga e sem bebê. É complicado para as crianças realizarem o que ocorreu. $\mathrm{Ou}$ ainda: M uito importante, pois o irmão maior necessita de ver o seu irmãozinho para não ficar triste e angustiado. Outros lembraram o quanto o programa facilita seu manejo com os filhos mais velhos. M uito bom, pois dá suporte aos pais para a explicação e o enten dimento da situação do bebê, para o irmão elaborar essa nova realidade.

Quanto às atividades desenvolvidas na visita as considerações também se mostraram favoráveis. Preparou minha filha para não se assustar com o tamanho do irmão e a situação do irmão. Ela ficou encantada com o bebê, fez cari- 
nho. Outros são bastante enfáticos em suas considerações: Ajuda aos pais a fortalecer o vínculo entre 0 irmão e o bebêe a inserir o irmão neste contexto, que mesmo sendo transitório, é muito doloroso para toda a família. A criança que se sente parte deste processo, se sente também importante e valorizada. $\mathrm{E}$ o bebê também é ben eficiado com isso. Outros comentários remetem as suas próprias dúvidas iniciais quanto à participação ou não no programa. Com certeza muito bom, pois nossa filha, na época com três anos, portouse sempre de maneira segura, nunca ficou assustada ou amedrontada pelo fato de o irmão estar em uma incubadora, entubado, em um ambiente hospitalar. A pós a volta para casa, sua relação com o irmão continuou tranqüila, sem maiores traumas pelo fato de ele ter ficado numa UTI. A única coisa que observamos foram reações normais de ciúmes entre irmãos, que aconteceriam independentemente de ele ter sido internado.

As famílias constataram que os resultados em relação aos irmãos que visitaram o bebê também foram positivos: Houve uma notória tranqüilidade do irmão com relação ao seu próprio cotidiano. Ficou mais fácil enfrentar as dificuldades do momento em si. O u avaliam a interação entre os filhos: Achamos que o bebê foi beneficiado pel os contatos tranqüilos que tinha semanalmente com a irmã, extremamente receptiva com o irmão, sempre feliz nos dias das visitas. Ou ainda os resultados no próprio comportamento dos pais já apresentado acima, a partir da observação clínica: 0 nosso filho pôde dimensionar a situação da irmã, sem criar maiores fantasmas e causar mais angústias nele e em nós, que já estávamos completamente tensos e angustiados. Ele se demonstrou tranqüilo e familiarizado depois da visita. Isso foi muito tranqüilizante para nós, sentir esse comprometimento e dedicação por parte das psicólogas. Ou seja, não estávamos sós nesta tarefa complicada de mostrar, explicar e inserir o nosso filho mais velho, neste contexto passageiro, mas sofrido.

Quanto às repercussões futuras do programa, as respostas sugerem que serão positivas: M ostrar a importância da união e participação de todos da família nesta situação. Lembraram ainda a questão da formação da relação fraterna: ... acho que ajuda a criar um vínculo afetivo entre os irmãos, e quando o bebê for para casa, imagino que a aceitação do novo membro da família seja mais fácil. Ou ainda: Ajudou muito a criança a aceitar o novo integrante da família.

Em relação aos aspectos negativos, os pais apontaram a existência de apenas uma opção de horário para a visita, o que acaba dificultando a partici pação de al gumas crianças em função do horário escolar.

\section{Respostas da equipe}

Indagados se as visitas interferem na rotina de cuidados, todos informaram que não. Questionados se a entrada das crianças oferece um conhecimento mais integral da família einterfere nos cuidados prestados ao bebê, os profissionais responderam que o programa não atrapalha em nada a assistência clínica (médica e de enfermagem) prestada à criança, permite observar e entender alguns comportamentos da família e torna a equipe mais humana. D eixamos de ser apenas profissionais, para sermos humanos e mais voltados para dentro de nós mesmos, pois lembramos de nossa família.

Quanto aos aspectos positivos do programa salientaram que o mesmo diminui tanto 0 estresse familiar como a ansiedade da criança após visita ao bebê; ajuda a equipe a conhecer a família, sua dinâmica e o paciente; ajuda na recuperação do bebê; ajuda o irmão diminuir suas fantasias sobre o nascimento do bebê; ajuda a família a olhar para a internação de um jeito diferente. Os comentários por escrito, da equipe mostram: Para a família participar mais do processo de cura e de integração do recémnascido ainda durante sua permanência no hospital. Para o irmão tornar o recém-nascido mais "tangível". Para a equipe, auxiliar a dar identidade ao paciente ( conhecer e entender melhor a composição da família)". Ou então: É bom para a família, e para o irmão que está aflito em casa, querendo conhecer o irmão que está internado. Estabelecem também uma relação com a meIhora do bebê: O bservo que a família participa. A recuperação do bebêé melhor. Ou entendem a visita como medida de proteção para com 0 irmão mais vel ho: $M$ ais positivos em relação às expectativas do irmão mais vel ho, que poderia fantasiar negativamente o que teria acontecido com o bebê. Ou ainda: Serve como um calmante para os baixinhos ansiosos e acaba com a ansiedade e curiosidades.

Quanto aos aspectos negativos, apenas houve um comentário: Talvez alguns irmãos fiquem impressionados e estressados com a situação do bebê.

Em relação à avaliação global do programa, afirmaram que diminui o estresse familiar, humaniza a equipe, diminui a ansiedade dos irmãos e dos pais além de manter os laços fami- 
liares - A cho muito válido, pois ajuda os familiares a superar os momentos difíceis. Ou ainda: Pela forma como é conduzido e pelo caráter inovador e humanizador, acho que este programa é um modelo! Avaliando a relação familiar: 0 programa dos irmãos é fantástico, pois ajuda a família a manter a ligação entre si. Além de diminuir 0 estresse familiar.

\section{Discussão dos resultados}

Os resultados descritos acima nos permitem afirmar sobre o val or e a eficácia de um programa de intervenção com este grupo de familiares. M ostram que acolher os irmãos dos bebês, num programa de visitas no ambiente de cuidados intensivos neonatais é benéfico pois inaugura a ligação fraterna, estimula a competência paterna e materna, trazendo uma maior tranqüilidade no contato com o bebê hospitalizado. O u seja, estimula a proximidade da fratria, diminui as fantasias, o medo, a angústia e a culpa que se tornaram inquilinos do espaço familiar deixado vago pelo bebê que nasceu, mas que ainda não pode ir para casa. 0 programa oferece um suporte para que cada personagem da família se considere um sujeito apto para o desempenho de suas atribuições neste momento. Portanto, oferece um resgate à auto-estima de todos os integrantes da família, estimulando a utilização de suas habilidades e suas competências para percorrerem caminhos novos, não conhecidos dos vínculos familiares. Por outro lado, ao participarem ativamente dos cuidados com o bebê, suas preocupações e suas ansiedades passam a ser compreendidas cognitivamente e afetivamente.

Como disseram os pais - o programa dá suporte aos pais e entendimento aos irmãos do que se passa com o bebê. Portanto, aqui se encontra uma das respostas quanto ao valor deste programa dirigido aos irmãos dos bebês, no que se refere à humanização no ambiente de cuidados intensivos neonatais e suas implicações na dinâmica familiar.

Algumas situações especiais têm merecido atenção e precisamos discutir. São experiências que devem ser lembradas e que nos mostraram a indicação de cuidados diferenciados para algumas crianças. Como com aquelas crianças que permanecem muito tempo no programa em função de uma internação prolongada do bebê. Com freqüência estes irmãos mais vel hos demandam do Serviço de Psicologia interven- ções individuais provenientes de seu cansaço, de sua falta de perspectiva em virtude do tempo longo que o bebê permanece no hospital, pela sensação de abandono que experimentam, especialmente das figuras parentais. N esses casos em que o bebê permanece por vários meses internado, ele requer, da figura materna, uma presença muito constante, o que aumenta a separação com o filho mais velho. M esmo que o tempo real, em número de horas dedicado a cada uma das crianças seja semel hante, o que ocorre é que a disponibilidade da dupla parental quanto à atenção, disponibilidade física e envolvimento se encontra prejudicada neste período. 0 bebê requer um envolvimento psíquico máximo, constante e intenso, mesmo quando os pais se encontram em casa, longe dele e do hospital. Seus pensamentos, suas preocupações como podemos acompanhar, permanecem próximos a incubadora, junto do bebê que deixaram no leito do hospital. Os demais filhos percebem isso e sentem-se prejudicados. Em função disso é da maior importância prover cuidados de outros familiares, em especial por meio dos avós ou ainda por meio de figuras importantes de ligação como tios ou padrinhos, buscando diminuir estas ausências e proporcionando novas formas de reabastecimento afetivo a estas crianças.

\section{A possibilidade da morte}

Acreditamos ser da maior importância discutirmos também nossas observações sobre aquelas crianças cujos irmãos possuem um diagnóstico de incompatibilidade com a vida. Sabemos todos que elas devem receber uma atenção especial com preocupação quanto à experiência de perda que irão viver e também quanto aos vínculos que desenvolvem com as pessoas do hospital. É extremamente recomendada a continuidade de um mesmo profissional acompanhando-os neste período. 0 que este irmão(ã) precisa é de proximidade e escuta diferenciada e individualizada, uma referência de estabilidade e de contenção da angústia que experimenta. Precisa de um suporte que o ajude na tessitura desta relação que se inicia de maneira muito instável e conflituosa.

Ao mesmo tempo a família deve sentir-se acolhida para que traga suas dúvidas sobre 0 futuro, sobre seus projetos familiares que necessitam grandes reformulações enquanto recebem orientações sobre como lidar com esta situação. Isto preocupa ainda mais quando es- 
ses irmãos encontram-se em idades próximas aos quatro e cinco anos de idade. É nesse momento que seu desenvolvimento permite e estimula indagações e curiosidades quanto a temas como finitude e morte. Desta forma, estas questões deixam de existir apenas no imaginário ou nas representações cognitivas das crianças para se transformarem numa experiência dura e cruel carregada de sentimentos dolorosos e angustiantes. Além disso, por serem acompanhados pela tristeza e pela sensação de impotência dos pais tornam-se ainda mais intensas.

0 acompanhamento posterior ao óbito, através de contatos com os pais, mesmo que por telefone, é sempre recomendável.

\section{Outras situações especiais}

Os irmãos que possuem uma história de vínculos iniciais diferentes como adoção, experiências de abandono ou perda de figuras de referência afetiva, podem apresentar comportamentos de ansiedade e agressividade no ambiente intensivo. Estas crianças em alguns momentos podem parecer hiperativas, impulsivas e dificultam muito seu manejo. Assim sendo, devem receber um acolhimento extremamente seguro, caloroso e próximo por parte da equipe. Respostas objetivas às suas perguntas, apresentação de regras para sua participação no programa ajudam em sua organização e diminuem a sua agitação.

Os irmãos visitantes egressos de internações neonatais formam um outro grupo muito especial. Em nenhum momento observamos medo, dificuldade em entrar naUTI, ansiedade em enfrentar o que para eles já é conhecido. Possivelmente a recepção calorosa da equipe à sua chegada, os comentários sobre como eles eram na incubadora, sobre sua forma de se comportar durante a internação, confirmam sua individualidade, resgatam sua história que portanto possui uma narrativa não só para a família mas para quem dela participou. Utilizam sua participação nas atividades lúdicas e gráficas como uma visita às suas memórias e seus registros que acreditamos sejam evocados, nesta situação, buscando el es mesmos uma revisão de sua história e de suas experiências.

\section{Comentários finais}

Como recomendação, a visita nunca deve ser realizada sem a concordância da criança. Ela poderá comparecer ao hospital por várias vezes sem aproximar-se do bebê. Tal conduta não caracteriza um problema, uma não aceitação ou uma dificuldade emocional. Da mesma forma nas internações prolongadas os irmãos visitantes podem apenas desejar serem recebidos através do programa, sem sequer se aproximarem do bebê. Ou apenas o visitam nos instantes finais do horário estabelecido.

Em relação à equipe foi confirmado que: Ao se criar este espaço (da visita dos irmãos aos bebês internados), delimita-se concretamente para as equipes que atuam nesse ambiente 0 fato de que todo bebê faz parte de uma história familiar que há de ser levada em conta por todos seus cuidadores (Braga \& M orsch, 2004). Como apurado nos questionários e nas observações de campo, também os cuidadores do hospital confirmam as repercussões do programa em sua conduta e em suas propostas de cuidados humanizados - deixamos de ser apenas profissionaise nos tornamos mais humanos, pensamos na nossa família. Esta frase traz consigo uma das idéias fundamentais para o processo de humanização hospitalar - a capacidade da empatia, imprescindível para quem deseja cuidar e não apenas tratar de um bebê que necessita de cuidados intensivos.

Nestes oito anos do programa Lembraramse de M im! participamos de muitas histórias, acompanhamos muitas dúvidas e observamos enfermeiros, técnicos de enfermagem responsáveis pelos cuidados dos bebês, médicos conversando e mesmo brincando com as crianças nos corredores do hospital ou junto dos bebês. Nos murais existentes nos corredores do hospital são encontradas fotos que registram alguns momentos da permanência dos bebês e suas famílias na unidade, imagens das crianças abraçadas a diferentes membros da equipe. Com freqüência estes profissionais se dirigem às crianças que freqüentam o programa chamando-as pelo nome, reconhecem quem são seus irmãos ou irmãs, comentam sobre a conduta dos bebês, explicitam semelhanças físicas ou posturais entre ambos, mostrando um envolvimento com estes novos participantes dos cuidados que propomos como humanizados. Atualmente faz parte da rotina das visitas um convite espontâneo realizado pelos técnicos de enfermagem para uma mais efetiva participação do irmão, nos cuidados para com o bebê, durante a visita. Eles são convidados a participar da alimentação do bebê, segurando a seringa no caso da gavagem; numa troca de fraldas; 
são chamados para observarem o sorriso do bebê, na incubadora, quando se aproximam.

Para as autoras deste estudo, estas condutas da equipe são extremamente facilitadoras do bem-estar das crianças visitadoras pois referem-se a ações que envolvem os irmãos mais velhos numa rotina de cuidado com os bebês, colaborando para a diminuição de suas fantasias de culpa diante da hospitalização do bebê. Sentirem-se aceitos e integrados pelos profissionais considerados donos do "saber cuidar" neste momento de tanta preocupação quanto à fragilidade do bebê traz repercussões imediatas e extremamente significativas em sua auto-estima e em sua competência fraterna.

Ao término deste artigo temos certeza de que num futuro próximo, devemos avaliar com os próprios irmãos sua participação neste programa. Também pensamos na importância de um estudo sobre as relações fraternas que ocorrem em situações especiais, independente da internação ter sido neonatal. A ocorrência de acidentes, doenças mais tardias, na primeira infância ou posteriormente traz, conforme podemos acompanhar em outras instituições, questões diferenciadas das que se dão neste período.

$M$ uitos pais ao visitarem posteriormente 0 hospital, ou em outros encontros, estimulam a realização de tais estudos ao relatarem acontecimentos significativos que acompanham nesta relação, após a hospitalização. Por outro lado, nesses anos todos, a cada semana, foi possível sentirmos pequenas mãos procurando pelas dos profissionais responsáveis pelo programa, ao ingressarem no espaço intensivo neonatal. Por breves momentos seguram-se firmes, apertam nossas mãos. Viver esta sensação é prazeroso e confirma a importância desta intervenção e deste cuidado. M as nada disto pode ser comparado ao momento que estas mãos se soltam para se dirigirem rápidas ao encontro da mãe próxima da incubadora, com o bebê no colo, ou do pai próximo ao bebê. N este momento, a proximidade familiar passa a ser a condutora desta trama que pertence àquele grupo que se debruça sobre o pequeno bebê. As demonstrações de carinho, os abraços, as lágrimas que surgem, os sorrisos imensos que substituem expressões de preocupação e dor dos irmãos, confirmam o quanto esta intervenção deve ser estimulada.

Para finalizarmos iremos relatar duas observações que registramos em nossos diários de campo. Bianca, de apenas três anos, no colo do pai, imediatamente após olhar para sua irmã recém-nascida, na incubadora, grita, com intensa alegria, para os avós e demais familiares que se encontravam fora da UTI: "Ela está bem!" Seu alívio ao encontrar a irmã, viva, grande, dormindo na incubadora, aparece nestas palavras que também serviram de apoio aos demais familiares. Ao conhecermos sua história foi possível compreendermos melhor esta sua conduta. Bianca participou de forma muito intensa nos cuidados pré-natais. Estava na consulta médica quando foi realizado o diagnóstico fetal de complicações cardíacas em sua irmã. Acompanhou todas as explicações e orientações médicas indicadas. Foi, portanto, junto de sua mãe, depositária de uma má notícia durante o período gestacional. Ao continuar compartilhando a história de sua irmã, ao encontrá-la bem na incubadora, passou a ter esperança e pode experimentar uma grande al egria. E pode então ser mensageira de uma boa notícia para sua família.

Já M atheus, em seus sábios cinco anos, nos primeiros segundos próximo ao seu irmão, na incubadora, afirmou: Quando você crescer a gente vai chutar caramujos juntos!, instaurando nesta fala a cumplicidade e o companheirismo próprios do vínculo fraterno.

\section{Colaboradores}

DS M orsch, responsável pela estruturação e implantação do Programa de Acolhimento aos I rmãos de Bebês Internados em UTI N eonatal - Lembraram-se de mim!, foi a orientadora deste estudo eJ Delamonica responsável pelo trabalho de campo. 


\section{Referências bibliográficas}

Bank S \& Kahn M 1988. El vínculo fraterno. 1a ed. Paidós, Buenos Aires.

Barrera QF, Sepúlveda B \& Weber U 1993. Participación materna en la atención del niño hospitalizado / $M$ other's participation in the attendance to hospitalized children. Rev. chil. pediatr 64(3):164-168.

Braga N \& M orsch DS 2003. Os irmãos na UTI N eonatal, pp. 97-106. In M E M oreira, NA Braga \& DS M orsch. Quando a vida começa diferente: o bebê e sua família na UTI neonatal. Fiocruz, Rio de Janeiro.

Braga N \& M orsch DS 2004. Cuidando da família: maternagem ampliada (pais, irmãos e avós), pp. 543-563. In M E M oreira, JM Lopes \& M Carvalho. 0 recémnascido de alto risco, teoria e prática do cuidar. Fiocruz, Rio de Janeiro.

Brasil 2002. M inistério da Saúde. M anual do Programa de A tenção humanizada ao Recém-N ascido de Baixo Peso - M étodo Canguru.

Committee on Fetus and Newborn 1985. Postpartum (neonatal) sibling visitation. Pediatrics 76(4):650.

Gray JE, Safran C, Davis RB et al. 2000. Baby CareLink: using the Internet and telemedicine to improve care for high-risk infants. Pediatrics 106(6):1318-1324.

Klaus M \& Kennell J 1993. Pais/bebês - o desenvolvimento do apego. Artes M édicas, Porto Alegre.
Kimberly A, M oore C, Coker K et al. 2003. Implementing potentially better practices for improving familycentered care in neonatal intensive care units: successes and challenges. Pediatrics 111(4):e450-e460.

Larguia M 2005. M aternidades centradas em la família M odelo Sardá. Disponível em <www.sarda.org.ar>. Acessado em 3/1/2005.

Montagu A 1988. Tocar: o significado humano da pele. Summus, São Paulo.

M orsch DS, Carvalho M \& Lopes JM 1997. Programa de visitação os irmãos aos bebês internados em UTI neonatal. Pediatria M oderna 3(7):481-488.

OakesJ 1993. Well siblings of sick children in pediatrics for parents. Disponível em <www.findarticles.com>. Acessado em 3/1/2005.

Rufo M 2003. I rmãos, como entender essa relação. Nova Fronteira, Rio de Janeiro.

Schwab F, Tolbert B, Bagnato S\& M aisels] 1983. Sibling visiting in a neonatal intensive care unit. Pediatrics 71(5):835-838

Scochi CG, Kokuday M LP, Riul MJS et al. 2003. Incentivando o vínculo mãe-filho em situação de prematuridade: as intervenções de enfermagem do hospital das Clínicas de Ribeirão Preto. Rev. Latino-Am. Enfermagem 11(4):539-543.

Artigo apresentado em 22/03/05

Aprovado em 25/04/05

Versão final apresentada em 12/05/05 